\title{
Research on Orientation and Methods of Undergraduate Interpretation Teaching
}

\author{
Jing $\mathrm{Li}^{1, \mathrm{a}}$ \\ ${ }^{1}$ Department of Foreign Language and Literature of Huanghuai University, Zhumadian, Henan, \\ China, 463000 \\ aemail,
}

Keywords: Orientation, Methods, Undergraduate Interpretation Teaching

\begin{abstract}
With the increasing globalization of the economy, the social demand for interpreters is increasing in order to meet this demand, more and more colleges and universities to set up undergraduate translation, and set up a master professional translation, interpretation becomes the main force personnel training, training translators increasingly professional, in this situation, undergraduate teaching English interpreters become interpreters talents infancy. In this paper, clear English undergraduate interpreting teaching position and goals, and to explore the undergraduate interpreting teaching mode from the elements before the start of courses to prepare teachers and teaching materials, teaching methods and content and assessment standards.
\end{abstract}

\section{Introduction}

With the globalization trend is increasingly evident, is translated in all areas of social life is playing an increasingly important role. But all Western culture as the main positions of University College translators and translation teaching, especially teaching specialized interpretation is much weaker. "Foreign Graduates learned in school listening, speaking, reading, writing and language and literature, to the community, from the most to be reflected on their interpretation and translation capability." Although there are a considerable number of foreign language faculty from college graduate of Western personnel engaged in interpretation and translation work, but these professionals engaged in translation by training at university are mostly just remember a word or sentence to accept teaching translation training, translation training in the true sense is mostly from long-term practice, so let the students to better adapt to the faster society, it is necessary to strengthen the teaching of interpreting course, "interpreters should become an important foreign language compulsory for high school students."

\section{Orientation of Interpretation Teaching}

As a bilingual communicative activities and means of communication, the purpose of interpreters is to help people realize the conversation and listener bilingual communication, through the use of language interpreters, so to speak. A language, relayed out with the B language. Since this process is not to pass a simple oral paraphrase the language code, but an understanding of the meaning of language after first relayed the process, that the interpreter in the integrated use of both languages in a very short time to listen to, record, interpret, and many say kinds of ability, according to the sign surface or verbal chain information system, and actively integrate quickly through the brain, analysis, judgment and reasoning, and uninterrupted participation in the cognitive system, final settlement of relations the semantic system. Therefore, the meaning of words is not the interpreter translated the words of the surface, but there are a series of translators heard the sound of words after the chain, use immediately stored in the brain related information primitives discrimination, analysis, reasoning and integration, and in line with the translation the method of language rules express this information. "Meaning the sum of discourse and textual meanings and is not a single word, but the meaning of the language with foreign language knowledge added cognitive outcomes." Therefore, in the process of interpreting, the interpreter was not translating languages, but in the quoted language meaning. If one minute can use 180 words to express ideas, three 
minutes 540 words are difficult to remember, and the interpreter was able to express the contents back, because he was listening, understanding and expression is no longer a language, there is a coherent logical chapter.

At the same time, generating language interpretation is a dynamic process, and the corresponding text meaning is produced in the dynamic process of language knowledge and awareness of the increasing integration of knowledge. Interpreting speech chain fleeting, do not allow the listener to stay on a verbal chain, especially simultaneous interpretation. Did not understand a word, or stay in the individual numbers, words, there will be a shortage of information and loss. So in the process of interpreting the interpreter must do multitasking, that translators have a strong ability to process information, capable of certain complex mode of operation can be simplified, and the operation of some process automation and stylized, and ultimately to a certain extent reduce the difficulty of processing the information. Thus, the training process is largely interpreters to / procedural automation-stage conversion process. The process of interpretation capacity development, improve the knowledge of the language to go through this process, but also interpreting skills acquired through this process. For the interpretation of this specialized skills, able to speak and write a foreign language is not necessarily, it is necessary to understand such a departing from the primitive language of the housing and then to express complex process automation procedures, and requires time and a lot of specialized interpreters training. Therefore, in interpreting the nature of the teaching position, we should focus on the characteristics of interpretation, develop appropriate teaching objectives and principles and take the appropriate teaching methods.

\section{The Purpose of Interpreting Teaching}

In general, every professional curriculum has a more macro objective, namely the professional training direction and goals. Each curriculum course has its own syllabus. Interpreter as a foreign language lesson in a professional course (course), which should be based on the amount of hours, the degree of students, seeking truth from facts, the person teaching, develop more practical, more specific teaching objectives.

Understand the interpretation of the form, nature, basic concepts and cognitive processes. High school students the opportunity interpretation class is usually the first contact with the interpretation, by trying to explain the interpretation and classroom teachers, students will gain general knowledge on interpreting such as various forms of interpretation, the role of interpretation, the standard principles of interpretation, the basic difference of interpretation and translation, interpretation, interpretation techniques and interpretation of cognitive processes. In particular, students need to understand the cognitive process of interpretation, understand the importance of procedural automation phase transition term cognitive knowledge, to enhance the awareness of the importance of classroom homework. These should be general knowledge, should not speak too abstract, too theoretical.

In order to cultivate the bilingual thinking ability of student, the first is to break the habit of thinking of students monolingual. The vast majority of students learning a foreign language is a way of adult foreign language acquisition methods, namely cognitive language first, and after the customary language, first learning the rules of language, through exercises, cognitive language into the habit of language, and some even stay the extent of cognitive language, did not achieve the customary language of conversion, specific performance is very convincing grammar, but English speaking out mistakes. Because prior learning grammar rules, students of English comprehension are also bound, forming a fixed syntax mode of thinking, it is difficult through the surface structure, capturing the deep significance of the structure. Therefore, to be "out of the original language of shell," conversion of meaning, the first fight old habits of thinking, to create a new habit of thinking, understanding of language from a new perspective.

To establish a certain bilingual responsiveness and basic interpretation Ability to establish bilingual thinking and interpretation ability of students in a course a semester cannot resolve the matter, but rather a long-term or lifetime. Learning process, many years engaged in the work of the interpreters translate still faces continuously improve their ability to interpretation problems. 
Interpreting university courses can be used as a starting point, the beginning of the learning cognitive process of interpretation is the beginning of skills development, focusing on training to enable students to learn the principles and methods of interpretation.

\section{The Methods of Interpreting Teaching}

The process of interpreting, understanding is a very important program. I did not understand the translation would be impossible. However, different from ordinary people understand the interpretation of the understanding of nature. Most people select only the information they are interested, they think you can ignore the other irrelevant or unimportant information, "Understanding the performance of a certain interpretation of the attention directed primitive whole, and the content of mental effort thinking process, purpose the original language is stored for interpretation." There is another layer of interpretation to understand the special nature: "Thinking interpreters understand this procedure is not completed after the interpretation and perception only started, but almost at the same time listen to distinguish the beginning." "Translators translate particularity lies precisely in the search to find information while also generating another verbal expression motivation, the formation of semantic early tracks, for subsequent verbal expression to prepare." That is to say, not only to understand the interpretation of comprehensive, detailed, and in this process there are two mental activities simultaneously. It is understood that this interpretation of the characteristics of the program, to the interpretation of the cognitive challenge, how to avoid interference between the two activities.

Students learned from Western point of view, the vast majority of adult learning, learning a foreign language through grammar rules. Thus, the students understanding of language syntax has become a fixed mode of understanding and hearing a composite structure of English, often have to wait a full sentence after finished to understand, but also tend to stay in the understanding of the surface structure of the language, not immediately deep people to structures of meaning. The first step in the training of listening comprehension, students generally do is to repeat the interpreters, after listening to a piece of content, does not require translation, requires only the effect, pay attention to cultivate a habit macro sense structure. Once the translation stage, primitive interference will increase, mainly due to difficulties in the way to understand the syntax. So the next step is to change students' listening comprehension traditional way and learn to understand punctuation. We know that every sentence structure of English, to have a number of "units of meaning" by means of various grammatical and non-grammatical cohesive links to sentence structure. Its meaning or significance of the unit structure point of view, the order is often linear, that is, extending the meaning of the order in which they appear in the sentence down, but the grammatical structure, morphology looks like a bunch of grapes, structure, structural relationship a front a rear.

The second aspect is Consecutive memory and notes methods. "In general can be considered short-term memory and interpreting work in the original language and perception, whereas the short-term memory and long-term memory and the contents of the original language interpreter, storing the relevant keywords and other information, in which long-term memory also learn the language and $\mathrm{B}$, and the 'preparation before translation' work of the interpreter has a special relationship." In the process of interpretation, short-term memory the most used, but limited capacity. "Because of the limited capacity of short-term memory, so do the interpretation of the time. Interpreters have to continue to come immediately for the transfer of information work. ... That will be temporarily stored in the temporary memory of the information and knowledge present in the permanent memory linked Contact the establishment faster, it means faster information processing, and then to the next note, or it is temporarily stored in permanent memory, so that short-term memory location can also empty out sooner. "This is the interpretation of memory works, but from the point of view of teaching, teachers need to consider two factors: First, the students' understanding of the original way, the word is caught or arrested structure of meaning. Second, students' ability to process information, primitive language features and characteristics of knowledge is causing difficulties in understanding and conversions. These two aspects have a great impact on the students' short-term memory capacity. Students in the beginner interpreters, often at a 
loss, do not remember the content down so worried about his bad memory.

In fact, the key is to understand there is no way to grasp, while listening comprehension is concerned that word, grammatical surface structure, rather than the structure of meaning. Like a string of beads, scattered on the plate, in a very short time to grab one by one, are slow, you cannot grab a few. Thus, the initial training, should not allow students to learn to take notes, but no notes should do more listening practice or interpretation, the first to master the correct way to understand the interpretation. Repeat the preceding interpretation method, which is an effective way to help students identify the primitive structure of meaning. After the students learn to recognize the significance of the structure or to develop the habit of grasping the meaning, and then learning to take notes, so focus on the notes will be placed on the significance of the structure, rather than isolated words, thereby reducing the activity of two notes and listening to each other interference.

The third aspect is the information conversion method. Transfer of information is a major part of the process of interpretation. Information converted through the completed between the two languages, but it is not a simple language the surface structure or code conversion, but the significance level of conversion. The past two decades, interpreters and researchers on the basis of sense structure, summarized the development of a set of effective interpreting punctuation skills, breaking the limitations of English sentence structure, reflecting the flexibility of interpretation. Comprehension alternate interpretation, especially side to understand the process of note taking side with simultaneous interpretation is similar to the process of understanding, it is based on meaning as a unit, according to the order of units of meaning emerged, linear process information.

\section{Conclusion}

In summary, we should position undergraduate Interpreting teaching on translation teaching, skills-based training, supplemented by theoretical teaching, let the students' training through interpreters have the basic conditions and quality ", from knowledge various aspects of the heritage, translation ability, psychological, mental reaction, cooperation and ethics as the interpretation work conducted in the future and lay a solid foundation.

\section{References}

[1] Anthony, Bruton. Language Learning Journal, Vol. 6 (2012) No 53, p.25-26

[2] Wang Yunhui, Wang Qunyong. Foreign Language Annals, Vol. 12 (2015) No 27, p.74-76

[3] Jing Jianfen, Hou XuSiem. Translation Communication, Vol. 30 (2015) No 19, p.144-145

[4] Wang Kuailiang. Review of Educational Research, Vol. 29 (2013) No 27, p.21-23

[5] Zhang Gongxu, Sun Jing. Chinese Translation, Vol. 8 (2011) No 27, p.57-60 